\title{
THE INFLUENCE OF STIMULUS DURATION ON DISCOMFORT GLARE FOR PERSONS WITH AND WITHOUT VISUAL CORRECTION
}

\author{
Michael Sivak \\ Michael J. Flannagan \\ Eric C. Traube \\ Shinichi Kojima
}

May 1997 
THE INFLUENCE OF STIMULUS DURATION ON DISCOMFORT GLARE FOR PERSONS WITH AND WITHOUT VISUAL CORRECTION

Michael Sivak

Michael J. Flannagan

Eric C. Traube

Shinichi Kojima

The University of Michigan

Transportation Research Institute

Ann Arbor, Michigan 48109-2150

U.S.A.

Report No. UMTRI-97-23

May 1997 
Technical Report Documentation Page

\begin{tabular}{|c|c|c|c|c|}
\hline $\begin{array}{l}\text { 1. Report No. } \\
\text { UMTRI-97-23 }\end{array}$ & \multicolumn{2}{|l|}{ 2. Government Accession No. } & \multicolumn{2}{|c|}{ 3. Recipient's Catalog No. } \\
\hline \multirow{2}{*}{\multicolumn{3}{|c|}{$\begin{array}{l}\text { 4. Title and Subtitle } \\
\text { The Influence of Stimulus Duration on Discomfort Glare } \\
\text { for Persons with and without Visual Correction }\end{array}$}} & \multicolumn{2}{|c|}{$\begin{array}{l}\text { 5. Report Date } \\
\text { May } 1997\end{array}$} \\
\hline & & & \multicolumn{2}{|c|}{$\begin{array}{l}\text { 6. Performing Organization Code } \\
302753\end{array}$} \\
\hline \multicolumn{3}{|c|}{$\begin{array}{l}\text { 7. Author(s) } \\
\text { Sivak, M., Flannagan, M.J., Traube, E.C., and Kojima, S. }\end{array}$} & \multicolumn{2}{|c|}{$\begin{array}{l}\text { 8. Performing Organization Report No. } \\
\text { UMTRI-97-23 }\end{array}$} \\
\hline \multirow{2}{*}{\multicolumn{3}{|c|}{$\begin{array}{l}\text { 9. Performing Organization Name and Address } \\
\text { The University of Michigan } \\
\text { Transportation Research Institute } \\
\text { 2901 Baxter Road } \\
\text { Ann Arbor, Michigan 48109-2150 U.S.A. }\end{array}$}} & \multicolumn{2}{|c|}{ 10. Work Unit no. (TRAIS) } \\
\hline & & & \multicolumn{2}{|c|}{ 11. Contract or Grant No. } \\
\hline \multirow{2}{*}{\multicolumn{3}{|c|}{$\begin{array}{l}\text { 12. Sponsoring Agency Name and Address } \\
\text { The University of Michigan } \\
\text { Industry Affiliation Program for } \\
\text { Human Factors in Transportation Safety }\end{array}$}} & \multicolumn{2}{|c|}{ 13. Type of Report and Period Covered } \\
\hline & & & & 14. Sponsoring Agency Code \\
\hline \multicolumn{5}{|c|}{$\begin{array}{l}\text { 15. Supplementary Notes } \\
\text { The Affiliation Program currently includes Adac Plastics, Bosch, Chrysler, Corning, Delphi Interior } \\
\text { and Lighting Systems, Denso, Ford (Automotive Components Division), GE, GM NAO Safety Center, } \\
\text { Hella, Hewlett-Packard, Ichikoh Industries, Koito Manufacturing, LESCOA, Libbey-Owens-Ford, } \\
\text { Magneti Marelli, North American Lighting, Osram Sylvania, Philips Lighting, PPG Industries, } \\
\text { Reflexite, Stanley Electric, TEXTRON Automotive, United Technologies Automotive Systems, Valeo, } \\
\text { Wagner Lighting, 3M Personal Safety Products, and 3M Traffic Control Devices. } \\
\text { Information about the Affiliation Program is available at http://www.umich.edu/ industry/ }\end{array}$} \\
\hline \multicolumn{5}{|c|}{$\begin{array}{l}\text { This laboratory study investigated the effects of stimulus duration and the nature of visual } \\
\text { correction on discomfort glare. The experimental setup simulated a nighttime driving situation with an } \\
\text { opposing glare source at } 3.5^{\circ} \text { of visual angle. There were } 25 \text { different glare stimuli, obtained by } \\
\text { combining each of five levels of duration (ranging from } 0.125 \text { to } 2 \text { seconds) with each of five levels of } \\
\text { illuminance (ranging from } 0.5 \text { to } 8 \text { lux). Two groups of subjects participated: those needing no visual } \\
\text { correction, and those needing correction and having both contact lenses and spectacles. The latter } \\
\text { group of subjects used their contact lenses in one half of the trials and their spectacles in the other half } \\
\text { of the trials. Discomfort glare was evaluated using the de Boer discomfort-glare scale. } \\
\text { Neither presence of correction (either contact lenses or spectacles versus no correction) nor } \\
\text { type of correction (contact lenses versus spectacles) had a statistically significant effect on discomfort } \\
\text { glare. When averaged across all subjects, both duration and illuminance had statistically significant } \\
\text { effects on discomfort glare, although subjects' discomfort judgments were less affected by duration } \\
\text { than by illuminance. Both relationships were well described by log-linear functions. Using these two } \\
\text { functions, we generated predictions about the likely changes in discomfort glare as a consequence of } \\
\text { selected changes in duration, and about the changes in duration and illuminance with equivalent effects } \\
\text { on discomfort glare. For example, a } 25 \% \text { reduction in duration is predicted to reduce discomfort glare } \\
\text { by } 0.2 \text { de Boer units, and be functionally equivalent to an } 11 \% \text { reduction in illuminance. However, } \\
\text { there were wide variations between subjects in the relationship between duration and discomfort glare. } \\
\text { These findings imply that, for the effectiveness of headlamp automatic-leveling systems and variable- } \\
\text { reflectance mirrors, the control of duration is less important than the control of peak illuminance, at } \\
\text { least for transient elevations in illuminance that are relatively brief. }\end{array}$} \\
\hline & & & & \\
\hline ne & He & & $\begin{array}{l}\text { 1. No. of Pag } \\
20\end{array}$ & 22. Price \\
\hline
\end{tabular}




\section{Acknowledgments}

Appreciation is extended to the members of the University of Michigan Industry Affiliation Program for Human Factors in Transportation Safety for support of this research. The current members of the Program are:

Adac Plastics

Bosch

Chrysler

Corning

Delphi Interior and Lighting Systems

Denso

Ford (Automotive Components Division)

GE

GM NAO Safety Center

Hella

Hewlett-Packard

Ichikoh Industries

Koito Manufacturing

LESCOA

Libbey-Owens-Ford

Magneti Marelli

North American Lighting

Osram Sylvania

Philips Lighting

PPG Industries

Reflexite

Stanley Electric

TEXTRON Automotive

United Technologies Automotive Systems

Valeo

Wagner Lighting

3M Personal Safety Products

3M Traffic Control Devices 


\section{Contents}

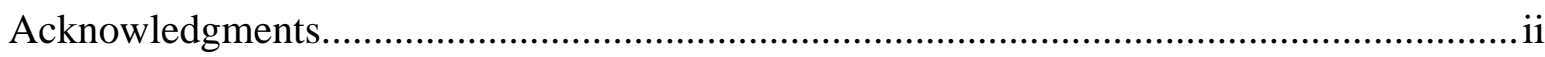

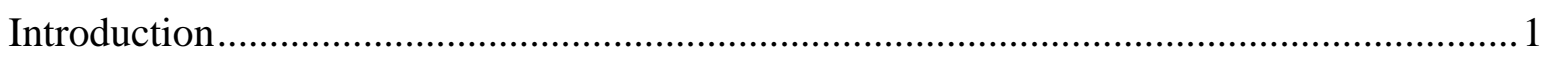

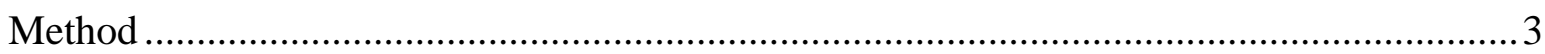

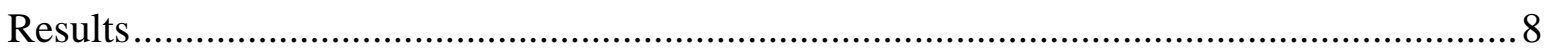

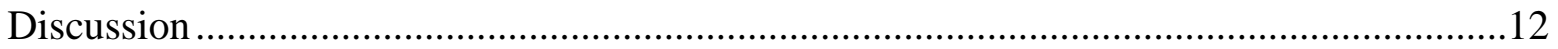

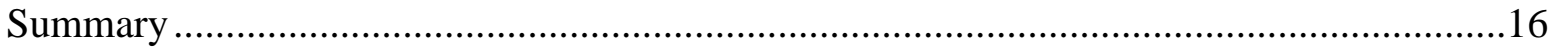

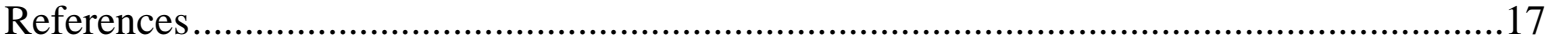




\section{Introduction}

The dynamic nature of driving results in continuously varying amounts of glare illumination reaching the eyes of the driver at night. This applies both to direct illumination from oncoming traffic, and to illumination from following traffic that is reflected via rearview mirrors. However, technology now exists to counteract changes in direct as well as indirect glare illumination. For direct illumination, auto-leveling devices are designed to compensate for changes in the pitch of the vehicle. Analogously, variable-reflectance mirrors function to adjust the amount of reflected illumination, based on the prevailing ambient conditions and the intensity of the glare source. In the design of these glare-reducing devices, the speed with which the device can respond to changing lighting conditions, and the consequent duration of the elevated illuminance at the eyes of the driver, are of some interest. Consequently, the present study focused on the effects of exposure duration on glare.

The traditional view is that glare has two separate effects on the observer. One aspect—disability glare-refers to an objective impairment in visual performance. The other aspect of glare - discomfort glare-refers to a subjective impression of discomfort. This study investigated discomfort glare only.

Discomfort glare is affected by physical variables such as illuminance, glare angle, and adaptation luminance (Schmidt-Clausen and Bindels, 1974). However, discomfort glare is also influenced by a variety of psychological factors, such as the range of other stimuli presented in the same experimental session (Olson and Sivak, 1984) and the difficulty of a concurrent task that the observer is engaged in (Sivak, Flannagan, Ensing, and Simmons, 1989). Consequently, caution needs to be exercised when discomfort-glare findings from a particular physical setup are applied to driving in general.

Of additional interest in this study were the effects of the presence and nature (contact lenses versus spectacles) of visual correction used by the observer on discomfort glare. There are reasons to expect that the presence of any visual correction might result in an increase in glare. This prediction is based on the fact that both spectacles and contact lenses introduce another potential source of light scatter due to dirt and abrasions.

There are several aspects of vision through spectacles and contact lenses that might influence vision. For example, as reviewed by Sheedy, Harris, Poon, and Sakuda (1992), there is more often residual astigmatism with contact lenses, contact lenses move with eye movements, and more accommodation and convergence are required for near sighted people to view near objects through contact lenses. Furthermore, it is reasonable 
to expect that, on average, spectacles scatter light more because of a higher likelihood of abrasions and dirt deposits. However, the evidence concerning actual differences in visual performance is mixed (e.g., Bernstein and Brodick, 1981; Sheedy et al., 1992), and we are not aware of any study on the potential differences in discomfort glare. 


\section{Method}

\section{Task}

The subjects' task was to rate discomfort glare from a peripherally presented light source. Subjects were instructed to continue focusing on a fixation point, and were reminded not to look directly at the glare source at any time during the study.

\section{Experimental setup}

Schematic diagrams of the experimental setup and the subject's view are shown in Figures 1 and 2. The subjects were seated at a table, with their chins in a chin rest to keep eye positions approximately constant throughout each session and across subjects. A small red LED constituted the fixation point. The glare stimulus was presented $3.5^{\circ}$ to the left of the fixation point, and behind a round aperture whose diameter was $25 \mathrm{~mm}$ $\left(0.5^{\circ}\right.$ of visual angle $)$. The light source for the glare stimulus was a halogen headlamp that was run at $12.8 \mathrm{~V}$. Presentation was controlled by an electronic timer and shutter. The fixation point, the glare stimulus, and subjects' eye positions were all centered at $1.15 \mathrm{~m}$ above the floor of the laboratory.

Both the fixation point and the glare source were $3 \mathrm{~m}$ from the subject, and they were surrounded by a background made of matte black foamboard. This black background extended about $7^{\circ}$ below the fixation point (and the glare source), and its

luminance near the two relevant stimuli was about $0.008 \mathrm{~cd} / \mathrm{m}^{2}$. Below it was a white foamboard that provided foreground adaptation analogous to that during night driving. It extended from $7^{\circ}$ below the fixation point to about $29^{\circ}$ below the fixation point, and it was tipped back at an angle of $35^{\circ}$. It was illuminated indirectly using a small incandescent lamp that was positioned under the subject's table. The luminance of the white foamboard was relatively uniform and it averaged about $1 \mathrm{~cd} / \mathrm{m}^{2}$ - the best available estimate of the average adaptation level while using low-beam headlamps on roads with no fixed illumination (Olson, Aoki, Battle, and Flannagan, 1990).

The illuminance at the subject's eyes was controlled by placing neutral density filters in between the light source and the shutter. 


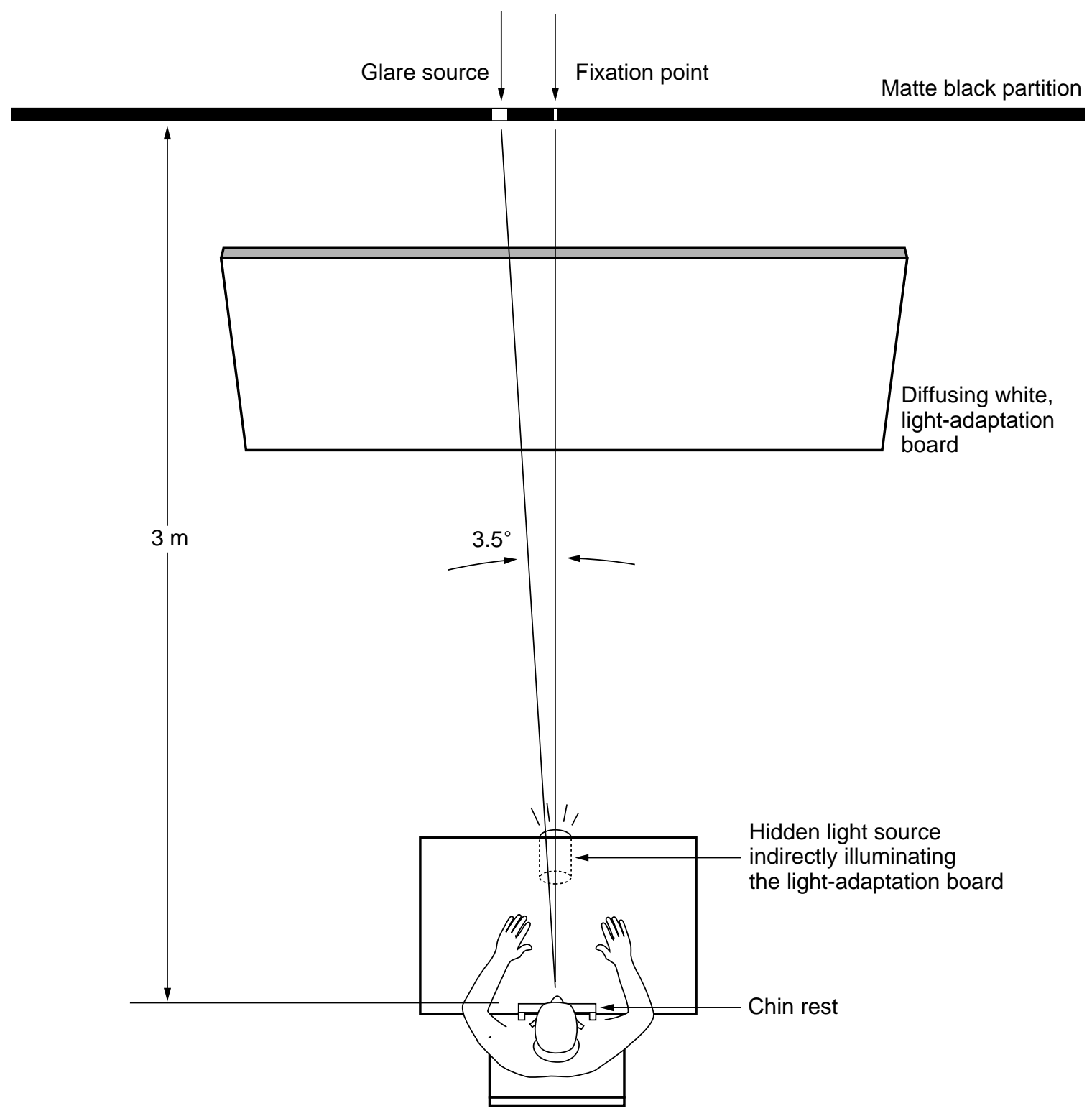

Figure 1. A schematic of the experimental setup. 


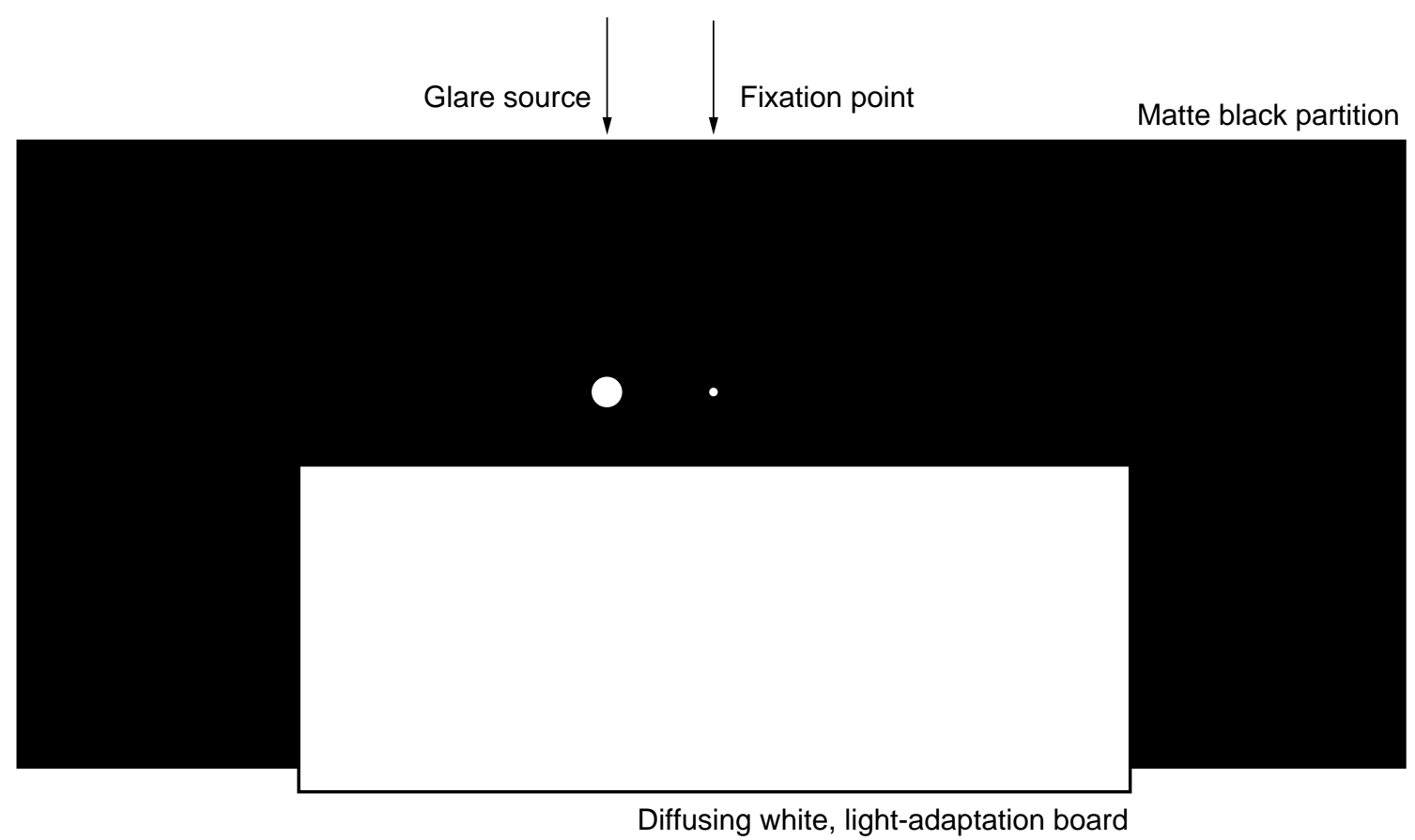

Figure 2. A schematic of the subject's view.

\section{Glare stimuli}

There were 25 unique glare stimuli, obtained by orthogonal combination of 5 levels of duration $(0.125,0.25,0.5,1$, and 2 seconds $)$ and 5 levels of illuminance at the subject's eyes $(0.5,1,2,4$, and 8 lux $)$. Photometry checks were performed each day to verify the illuminance levels.

\section{Response scale}

Subjects were asked to use the de Boer scale for their assessment of discomfort glare. This scale has been used extensively to evaluate glare in night driving situations (Bhise, Swigart, and Farber, 1975; de Boer, 1967). It is a 9-point scale with qualifiers only for the odd points as follows: 1 (unbearable), 2, 3 (disturbing), 4, 5 (just acceptable), 6, 7 (satisfactory), 8, 9 (just noticeable).

A copy of the de Boer scale was present on the table where the subjects were seated and was in clear view throughout the entire study. 


\section{Subjects}

Sixteen paid subjects, all licensed drivers, participated in the study. There were two groups of eight subjects. One group consisted of persons who did not use any visual correction. The other group consisted of persons who used both contact lenses and spectacles in daily life. They were asked to use one type of correction during one half of the study, and the other type in the other half of the study. All of the subjects in this latter group were near-sighted; six of them used soft contact lenses and two used gaspermeable hard contact lenses. There were six females and two males in each group. The ages and high-contrast visual acuities of the subjects in the two groups were similar (see Table 1).

Table 1

Ages and visual acuities of the subjects.

\begin{tabular}{|c|c|c|c|c|c|c|}
\hline \multirow{2}{*}{ Group } & \multicolumn{4}{|c|}{ Ages } & \multicolumn{3}{c|}{ Visual acuities } \\
\cline { 2 - 7 } & Min & Max & Mean & Best & Worst & Mean \\
\hline Without correction & 20 & 42 & 28.6 & $20 / 13$ & $20 / 20$ & $20 / 14.9$ \\
\hline With correction & 20 & 43 & 29.1 & & \\
\hline with spectacles & & & $20 / 13$ & $20 / 18$ & $20 / 15.9$ \\
\hline with contact lenses & & & $20 / 13$ & $20 / 22$ & $20 / 17.5$ \\
\hline
\end{tabular}

\section{Design}

Each session consisted of a total of 100 trials presented in four blocks. Each block contained all 25 combinations of the five durations and the five illuminances, in a randomized order. For the subjects with correction, the first two blocks were run with one type of correction, and the second two blocks with the other type of correction. Thus, for these subjects there were two replications of each combination of duration and illuminance under each type of correction. The order of the type of correction was counterbalanced. For the subjects without any correction, the four blocks did not differ (except for a different randomized sequence of the 25 trails). Consequently, these subjects received four replications of each combination of duration and illuminance. 


\section{Procedure}

Subjects were run individually in sessions lasting about one hour each. Subjects' visual acuity was tested using a Vision Tester OPTEC 2000P made by Stereo Optical Co. For those subjects who wore both contacts and spectacles, visual acuity was assessed twice, once for each type of correction.

Subjects were then brought into the laboratory, where they were allowed to adapt to the prevailing lighting condition for 10 minutes. During this time, subjects were read the instructions and any questions they had were answered.

An experimenter who called out the trial numbers and wrote down the subject's responses was seated behind and to the right of the subject. Another experimenter was stationed behind the large black partition in front of the subject, controlling the duration and illuminance of the glare source. After the first experimenter called out the trial number, the second experimenter presented the glare stimulus. Once the glare shutter closed, subjects called out their response using one of the nine numbers from the de Boer discomfort-glare scale. Approximately three to four trials were presented every minute.

After each block of 25 trials, subjects were given a short break. The subjects who wore corrections were instructed to change them after the second block of trials. The subjects without correction were given a break similar in length to the time it took the other subjects to change their type of correction. No practice trials were given. 


\section{Results}

To evaluate the effects of the type of visual correction on discomfort glare, an analysis of variance was performed on the data from the eight subjects who were tested with both contact lenses and spectacles. The dependent variable was the discomfort-glare rating on the de Boer scale. The independent variables were the type of visual correction (contact lenses or spectacles), illuminance at the eyes of the observer $(0.5,1,2,4$, or 8 lux), duration $(0.125,0.25,0.5,1$, or 2 seconds), and order (first or second). All independent variables were within-subject.

The main result of this analysis was that the effect of the type of visual correction was not statistically significant, $F(1,7)=2.5, p=.16$, although there was a tendency for contact lenses to result in more glare than spectacles (mean de Boer ratings of 5.1 and 5.3, respectively). Therefore, in the subsequent analyses the data for the two types of visual correction were combined.

An analysis of variance was then performed for all 16 subjects in which the independent variables were visual correction (present or absent), illuminance $(0.5,1,2,4$, or 8 lux), duration $(0.125,0.25,0.5,1$, or 2 seconds), and order (first, second, third, or fourth). Visual correction was the only between-subjects variable.

Although there was a tendency for persons with visual correction to report more glare than persons without correction (mean de Boer ratings of 5.2 and 5.7, respectively), this effect failed to reach statistical significance, $F(1,14)=3.7, p=.07$.

The effect of duration was statistically significant, $F(4,56)=14.8, p=.001$, with longer durations resulting in more discomfort (see Figure 3). (For this and all other tests involving within-subject independent variables with more than two levels, the Greenhouse-Geiser adjustment was used.) When the data were combined across all subjects, the best-fitting log-linear relationship accounted for $99 \%$ of the variance in discomfort glare among the five levels of duration $\left(\mathrm{r}^{2}=.99\right)$. However, a more complex picture emerged when the data for the individual subjects were examined. Specifically, there were major variations across subjects in both the slope of the best-fitting function and in terms the variance accounted for (see Table 2). 


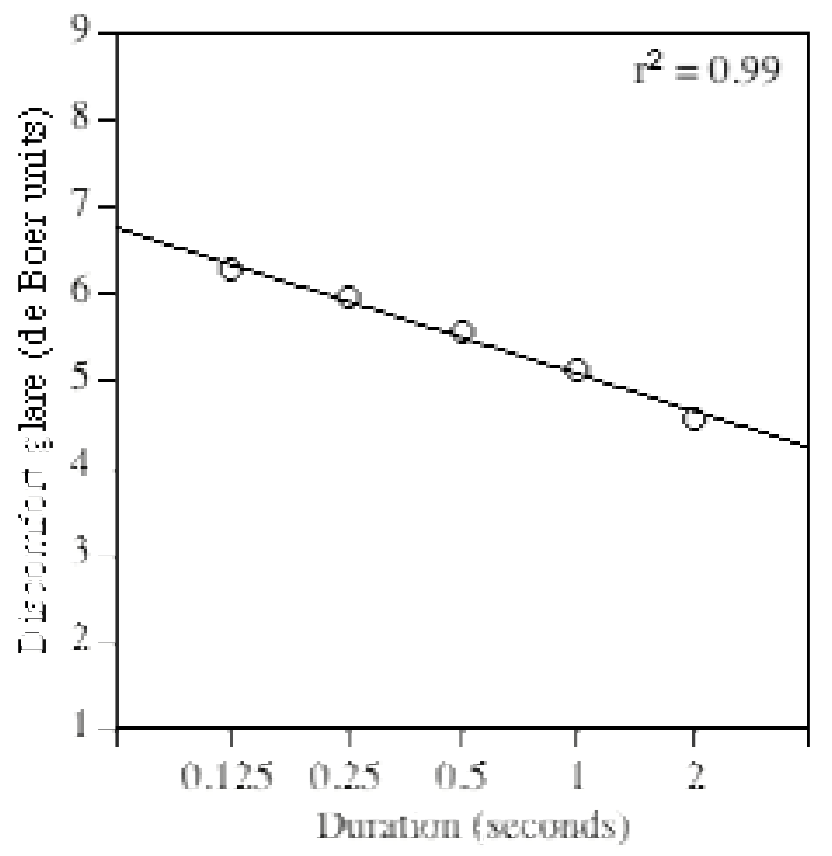

Figure 3. The effect of duration on discomfort glare for all 16 subjects. (Duration is plotted on a logarithmic scale. Lower de Boer units indicate more discomfort.)

Table 2

Individual differences in the slope and variance accounted for by the best fitting loglinear functions of duration and discomfort glare.

\begin{tabular}{|l|c|c|}
\hline & $\begin{array}{c}\text { Slope (de Boer units } \\
\text { divided by log duration) }\end{array}$ & $\begin{array}{c}\text { Variance accounted for } \\
(\%)\end{array}$ \\
\hline \hline Median & -.278 & 83.8 \\
\hline Minimum & -1.745 & 4.9 \\
\hline Maximum & $.190^{*}$ & 99.4 \\
\hline
\end{tabular}

*Only one slope was positive. 
The effect of illuminance was also statistically significant, $F(4,56)=122.0, p=$ .0001 , with higher levels of illuminance resulting in greater discomfort (see Figure 4). When the data were combined across all subjects, the best-fitting log-linear relationship accounted for $99 \%$ of the variance in discomfort glare among the five levels of illuminance $\left(\mathrm{r}^{2}=.99\right)$. The slopes and variances accounted for by the best-fitting loglinear functions for each individual subject are summarized in Table 3. The effect of order was not statistically significant, $F(3,42)=2.9, p=0.07$.

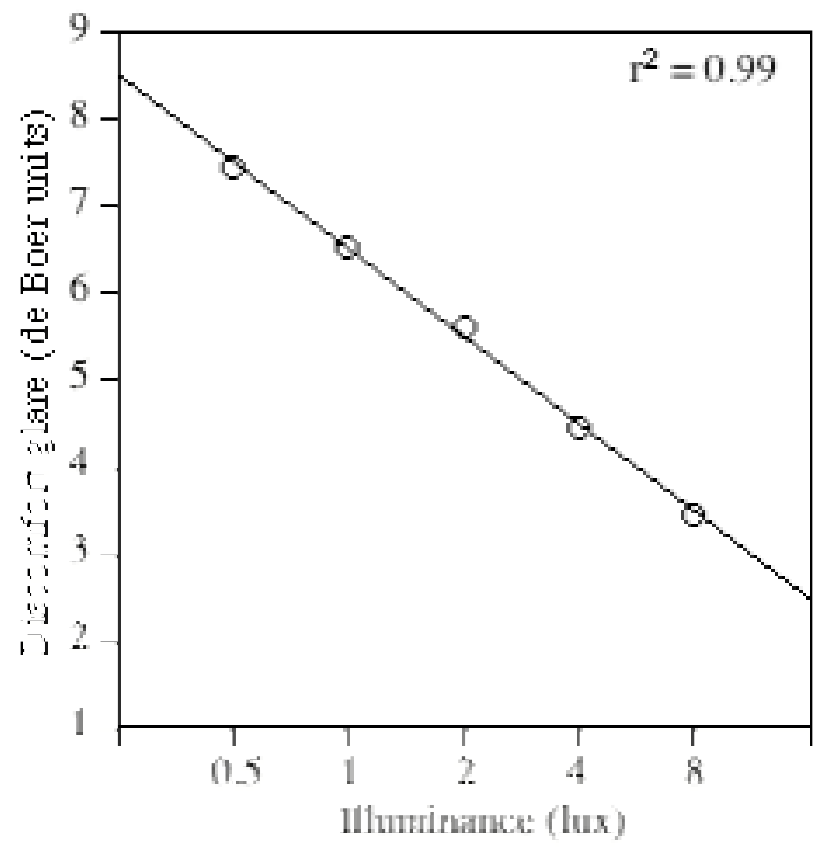

Figure 4. The effect of illuminance on discomfort glare for all 16 subjects. (Illuminance is plotted on a logarithmic scale. Lower de Boer units indicate more discomfort.)

Table 3

Individual differences in the slope and variance accounted for by the best fitting loglinear functions of illuminance and discomfort glare.

\begin{tabular}{|l|c|c|}
\hline & $\begin{array}{c}\text { Slope (de Boer units } \\
\text { divided by log illuminance) }\end{array}$ & $\begin{array}{c}\text { Variance accounted for } \\
(\%)\end{array}$ \\
\hline \hline Median & -.998 & 98.4 \\
\hline Minimum & -1.635 & 90.1 \\
\hline Maximum & -.390 & 100.0 \\
\hline
\end{tabular}


Only three interactions were statistically significant. Two of them involved order, and thus were not of major interest. The remaining, marginally significant interaction involved duration and visual correction, $F(4,56)=4.2, p=.05$. Specifically, the effect of duration was greater for persons with visual correction than for those without.

The levels of illuminance and duration were selected in such a way that there would be several combinations of those levels with the same total amount of light (determined by the product of illuminance and duration). For example, five of the conditions produced the total amount of light of 1 lux x seconds. These five conditions were as follows: 0.5 lux, 2 seconds; 1 lux, 1 seconds; 2 lux, 0.5 seconds, 4 lux, 0.25 seconds; and 8 lux, 0.125 seconds. Figure 5 presents the relationship of total amount of light and discomfort glare. As a first approximation, log total amount of light is a good predictor of glare, accounting for $84 \%$ of the variance $\left(\mathrm{r}^{2}=.84\right)$. However, the data also show systematic deviations from this pattern. Specifically, for each level of the total amount of light, the least glaring combination was always the one with the lowest illuminance and the longest duration, while the most glaring combination was always the one with the highest illuminance and the shortest duration. For example, for the 1 lux x seconds level, the least glaring combination was 0.5 lux, 2 seconds, while the most glaring combination was 8 lux, 0.125 seconds.

The finding that a simple product of illuminance and duration does not fully account for discomfort ratings, as illustrated in Figure 5, can also be deduced from the fact that changes in log duration have less effect on discomfort glare than equal changes in log illuminance (see Figure 3 and 4). If there were an even tradeoff between duration and illuminance the slopes in Figures 3 and 4 would be equal. 


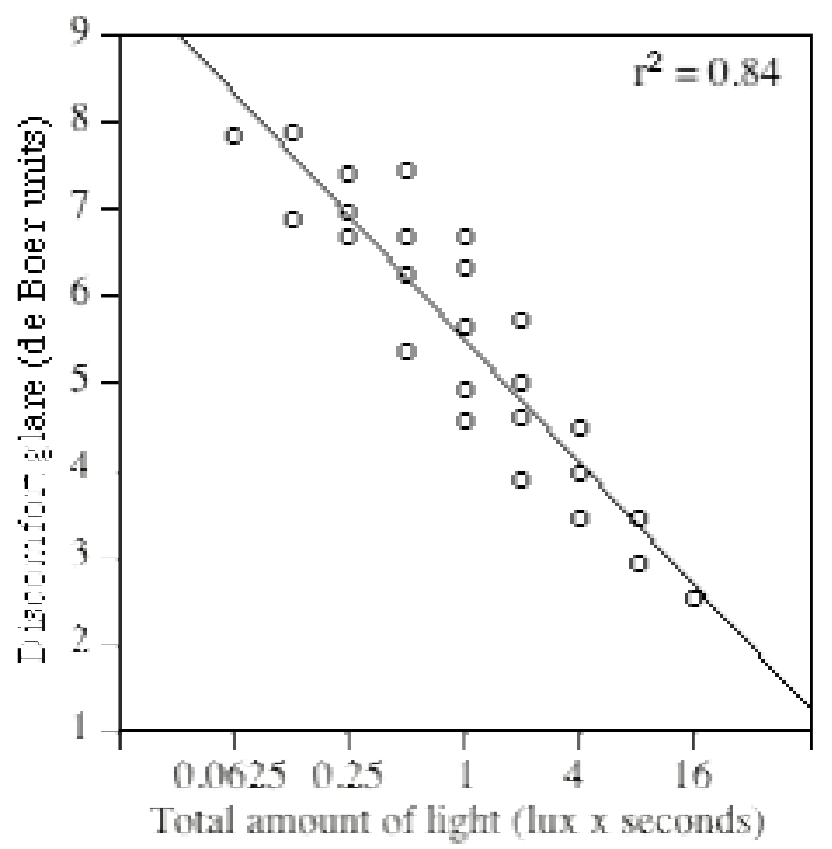

Figure 5. The effect of total amount of light (illuminance times duration) on discomfort glare. (Total amount of light is plotted on a logarithmic scale. Lower de Boer units indicate more discomfort.) 


\section{Discussion}

\section{Basic findings}

This study found that subjects reported approximately the same level of discomfort glare whether they wore their contact lenses or their spectacles. In addition, discomfort glare did not differ significantly between subjects who had no visual correction and those who wore either contact lenses or spectacles.

Duration had a statistically significant effect on discomfort glare, with longer durations resulting in more glare (see Figure 3). When averaged across all subjects, the data were well fitted by a log linear relationship. However, there were major differences among the individual subjects in how duration affected discomfort glare. Both the slope and the variance accounted for by the best-fitting functions varied widely across subjects (see Table 2). Furthermore, the effect of duration on discomfort glare was more pronounced for persons with visual correction than for those without visual correction. The mechanism for this effect is not clear. Consequently, it is possible that this is a spurious finding.

Illuminance had a statistically significant effect on discomfort glare, with higher illuminances resulting in more glare (see Figure 4). When averaged across all subjects, the data were well fitted by a log linear relationship. Furthermore, the slopes and variances accounted for were relatively consistent across subjects (see Table 3).

The effect of illuminance was greater than that of duration. This was evident from the fact that, for the same proportional change, the slope of the effect of illuminance was greater than the slope of the effect of duration (compare Figures 3 and 4).

\section{Application of the findings}

The fact that the effect of duration was smaller and more variable than that of illuminance implies that for mitigating the effects of transient elevations in glare light the control of duration is less important than the control of peak illuminance. Because the effect of duration (when averaged across all subjects) was well described by a log-linear function, there is no apparent "knee" or breakpoint in the relationship beyond which glare effects of increased duration are accelerated. However, using the best-fitting log-linear function between duration and discomfort glare (de Boer $=-1.405 \log$ seconds +5.052 )

one can calculate the expected effects of changes in duration on discomfort glare. This was done in Table 4 for four selected reductions in duration. For example, the 
information in Table 4 indicates that a $25 \%$ reduction in duration (e.g., a change from 1 to 0.75 seconds) is expected to lessen discomfort glare by about 0.2 de Boer units.

The effect of illuminance (when averaged across all subjects) also was well described by a log-linear function. Using the best-fitting log-linear functions for the relationships between illuminance and discomfort glare (de Boer index $=-3.337$ log lux + 6.480) and between duration and discomfort glare (de Boer index $=-1.405 \log$ seconds + 5.052 ), one can calculate for different reductions in duration the corresponding reductions in illuminance necessary for equivalent changes in discomfort glare (and vice versa). This was done in Table 5 for four selected reductions in duration. For example, the information in Table 5 indicates that a $25 \%$ reduction in duration (e.g., a change from 1 to 0.75 seconds) has about the same effect on discomfort glare as an $11 \%$ reduction in illuminance (e.g., a change from 1 to 0.89 lux).

Table 4

Expected changes in discomfort glare as a function of decreases in glare duration. (Based on the best-fitting log-linear function relating duration and discomfort glare.)

\begin{tabular}{|c|c|}
\hline Decrease in glare duration $(\%)$ & Decrease in glare (increase in de Boer units) \\
\hline \hline 10 & 0.1 \\
\hline 25 & 0.2 \\
\hline 50 & 0.4 \\
\hline 75 & 0.8 \\
\hline
\end{tabular}

Table 5

Decreases in illuminance that have corresponding changes on discomfort glare as a selected set of decreases in duration. (Based on the best-fitting log-linear functions relating duration and discomfort glare, and illuminance and discomfort glare.)

\begin{tabular}{|c|c|}
\hline Decrease in duration $(\%)$ & Equivalent decrease in illuminance $(\%)$ \\
\hline \hline 10 & 4 \\
\hline 25 & 11 \\
\hline 50 & 25 \\
\hline 75 & 44 \\
\hline
\end{tabular}




\section{Caution}

When the data were averaged across all subjects, the relationships between duration and discomfort glare, and between illuminance and discomfort glare were well described by log-linear functions. However, in contrast to the effect of illuminance on discomfort glare, which was relatively similar across the subjects, the effect of duration on discomfort glare varied substantially from subject to subject. Furthermore, the subjects with visual correction appeared to be more sensitive to changes in duration than those without visual correction. Consequently, the tradeoff between duration and illuminance varied from subject to subject, and there is some indication that it might be different for persons with and without visual correction. However, our calculations concerning the expected change in glare as a function of changes in duration (Table 4) and the equivalent changes in duration and illuminance (Table 5) should be valid for the average driver. 


\section{Summary}

This laboratory study investigated the effects of stimulus duration and the nature of visual correction on discomfort glare. The experimental setup simulated a nighttime driving situation with an opposing glare source at $3.5^{\circ}$ of visual angle. There were 25 different glare stimuli, obtained by combining each of five levels of duration (ranging from 0.125 to 2 seconds) with each of five levels of illuminance (ranging from 0.5 to 8 lux). Two groups of subjects participated: those needing no visual correction, and those needing correction and having both contact lenses and spectacles. The latter group of subjects used their contact lenses in one half of the trials and their spectacles in the other half of the trials. Discomfort glare was evaluated using the de Boer discomfort-glare scale.

Neither presence of correction (either contact lenses or spectacles versus no correction) nor type of correction (contact lenses versus spectacles) had a statistically significant effect on discomfort glare. When averaged across all subjects, both duration and illuminance had statistically significant effects on discomfort glare, although subjects' discomfort judgments were less affected by duration than by illuminance. Both relationships were well described by log-linear functions. Using these two functions, we generated predictions about the likely changes in discomfort glare as a consequence of selected changes in duration, and about the changes in duration and illuminance with equivalent effects on discomfort glare. For example, a 25\% reduction in duration is predicted to reduce discomfort glare by 0.2 de Boer units, and be functionally equivalent to an $11 \%$ reduction in illuminance. However, there were wide variations between subjects in the relationship between duration and discomfort glare. These findings imply that, for the effectiveness of headlamp automatic-leveling systems and variablereflectance mirrors, the control of duration is less important than the control of peak illuminance, at least for transient elevations in illuminance that are relatively brief. 


\section{References}

Bernstein, I. H. and Broderick, J. (1981). Contrast sensitivities through spectacles and soft contact lenses. American Journal of Optometry and Physiological Optics, 58, 309-313.

Bhise, V. D., Swigart, T. F., and Farber, E. I. (1975). Development of a headlamp dimming request prediction model. In R. N. Hale, R. A. McKnight, and J. R. Moss (Eds.) Human factors in our expanding technology (Proceedings of the 19th annual meeting of the Human Factors Society) (pp. 284-295). Santa Monica, CA: The Human Factors Society.

de Boer, J. B. (1967). Visual perception in road traffic and the field of vision of the motorist. In J. B. de Boer (Ed.), Public lighting. Eindhoven, The Netherlands: Philips Technical Library.

Olson, P. L., Aoki, T, Battle, D. S., and Flannagan, M. J. (1990). Development of a headlight system performance evaluation tool (Report No. UMTRI-90-41). Ann Arbor, MI: The University of Michigan Transportation Research Institute.

Olson, P. and Sivak, M. (1974). Discomfort glare from automotive headlights. Journal of the Illuminating Engineering Society, 13, 296-303.

Schmidt-Clausen, H. J. and Bindels, J. T. H. (1974). Assessment of discomfort glare in motor vehicle lighting. Lighting Research and Technology, 6, 79-88.

Sheedy, J. E., Harris, M. G., Poon, L., and Sakuda, T. (1992). Task performance with contact lenses and spectacles. Optometry and Visual Science, 69, 337-341.

Sivak, M., Flannagan, M. J., Ensing, M, and Simmons, C. J. (1989). Discomfort glare is task dependent. International Journal of Vehicle Design, 12, 152-159. 